BMJ Open Sport \& Exercise Medicine

\title{
Injury prevention exercise programmes in professional youth soccer: understanding the perceptions of programme deliverers
}

\author{
James O'Brien, Caroline F Finch
}

To cite: O'Brien J, Finch CF. Injury prevention exercise programmes in professional youth soccer: understanding the perceptions of programme deliverers. BMJ Open Sport Exerc Med 2016;2:e000075.

doi:10.1136/bmjsem-2015000075

- Prepublication history for this paper is available online To view these files please visit the journal online (http://dx.doi.org/10.1136/ bmjsem-2015-000075).

Accepted 28 October 2015

CrossMark

\section{Australian Centre for}

Research into Injury in Sport and its Prevention (ACRISP), Federation University

Australia, Ballarat, Victoria, Australia

\section{Correspondence to} James O'Brien; ja.obrien@ federation.edu.au

\section{ABSTRACT}

Background: There are well-known challenges to implementing injury prevention strategies in amateur soccer, but information from other soccer settings is scarce. This cross-sectional survey analysed the injury prevention perceptions of soccer coaches, fitness coaches and physiotherapists from 4 male teams in a professional youth soccer academy.

Methods: The respondents $(n=18)$ completed a webbased survey relating to lower limb (LL) soccer injuries, the value and practicality of injury prevention exercise programmes (IPEPS) in general and, more specifically, the IPEP endorsed by FIFA, the FIFA 11+. Results: There were very high levels of agreement regarding players' susceptibility to LL injury and the seriousness of these injuries. Respondents agreed unanimously that players should perform evidencebased injury prevention exercises. Despite $61 \%$ of respondents having previously heard of the FIFA 11+, just $6 \%$ reported current use of the full programme, with a further $22 \%$ reporting modified use. $22 \%$ believed the FIFA 11+ contained adequate variation and progression for their team and $78 \%$ felt it needed improvement. Respondents identified multiple barriers and facilitators to maintaining IPEPs, relating either to the programme content (eg, exercise variation), or the delivery and support of the programme (eg, coach acceptance).

Conclusions: The coaches, fitness coaches and physiotherapists of professional youth teams support the use of IPEPs, but enhancing their impact requires tailoring of programme content, along with adequate delivery and support at multiple levels. The findings suggest that the FIFA 11+ needs modification for use in professional youth soccer teams.

\section{INTRODUCTION}

Soccer is the world's most popular sport with over 260 million participants worldwide. ${ }^{1}$ Lower limb (LL) injuries are common in soccer and the negative impacts of these injuries have been well documented. ${ }^{2-7}$ Recently, injury prevention strategies for soccer have gained increased research

\section{What are the new findings}

- Coaches, fitness coaches and physiotherapists of professional youth soccer teams support the use of injury prevention exercise programmes (IPEPS).

- The majority of respondents were aware of the FIFA 11+, but less than a third used the programme and mostly in a modified form.

- Multiple challenges to implementing IPEPS in professional youth teams were identified.

attention, particularly the use of injury prevention exercise programmes (IPEPs). The efficacy of IPEPs in amateur soccer teams has been established in large-scale randomised controlled trials (RCTs). ${ }^{8-10}$ The Knaekontroll programme reduced the overall rate of anterior cruciate ligament (ACL) injuries by $64 \%$ in a RCT including over 4500 amateur female soccer players. ${ }^{8}$ The FIFA 11+, an IPEP endorsed by the FIFA, significantly reduced injuries in large-scale RCTs of amateur female ${ }^{9}$ and male players ${ }^{10}$ as well as collegiate male players. ${ }^{11}$

Alongside growing support for IPEP efficacy, evidence of significant challenges to implementing these programmes has emerged. ${ }^{12}$ These challenges span aspects of programme reach, adoption, compliance and maintenance, aligning closely with the implementation challenges identified in other team ball sports ${ }^{13-19}$ and other health-related fields. ${ }^{20-23}$ To date, the most commonly reported implementation challenges relate to programme compliance (also termed adherence or fidelity). This refers to the extent to which an IPEP is performed as intended. High compliance to IPEPs has been associated with greater injury reductions. ${ }^{11}{ }^{24-26}$ For example, a subsequent analysis of the aforementioned Knaekontroll $\mathrm{RCT}^{8}$ illustrated that players with high 
compliance experienced an $88 \%$ lower rate of ACL injury, compared with players with low compliance, who did not differ from controls. ${ }^{24}$ However, achieving adequate compliance can be challenging. ${ }^{27-29}$

Enhancing the adoption of IPEPs has also been identified as a major implementation challenge. ${ }^{12}{ }^{30}$ Despite extensive promotion of the FIFA $11+$ by soccer's international governing body since 2009, just $10 \%$ of the member soccer associations have actually endorsed the programme. ${ }^{12}$ Coaches have been identified as important adoption targets for IPEPs in amateur soccer, ${ }^{12}$ whereas other staff members (eg, physiotherapists and fitness staff) represent key programme deliverers in professional and collegiate soccer settings. ${ }^{31-33}$ In recent studies, just $20 \%$ of female soccer team coaches in $\mathrm{Utah}^{34}$ and $21 \%$ of female high school soccer and basketball coaches in Oregon ${ }^{35}$ reported using an IPEP. Among coaches of public high school soccer and basketball teams in Chicago, only $37 \%$ agreed to participate in an IPEP trial. ${ }^{36}$ Injury prevention knowledge gaps among players, coaches and parents have been identified in both male ${ }^{37}$ and female ${ }^{38} 39$ amateur soccer communities and also in other team ball sports settings. ${ }^{14} 1517$ In one recent study of youth male soccer players, $79 \%$ had not heard of the FIFA $11+{ }^{37}$

Improving IPEP maintenance represents another key challenge in enhancing the impact of IPEPs, but information on programme maintenance is rare. In a systematic review on the reporting of team ball sport IPEP trials, maintenance was the least reported of all implementation aspects. ${ }^{40}$ A recently published, 3-year follow-up ${ }^{41}$ to the previously mentioned Knaekontroll $\mathrm{RCT}^{8}{ }^{\text {investigated the maintenance of the programme }}$ by amateur female soccer coaches. Use of the programme by still active coaches, in some form, was very high $(82 \%$ for intervention group coaches and $68 \%$ for control group coaches). However, the majority performed the IPEP less frequently than recommended and around three-quarters had modified the content of the programme. ${ }^{41}$

Research on IPEP implementation in professional soccer settings remains scarce, but awareness of the impact of implementation on injury prevention success in professional teams is growing. ${ }^{42}{ }^{43}$ In a study of coaches from elite junior female teams, ${ }^{44}$ high levels of coach intent to deliver an IPEP were observed following a coach workshop. Despite this, only 53\% of coaches actually adopted an IPEP during the following season. A recent study in high-level professional male soccer investigated use of the evidence-based Nordic Hamstring (NH) exercise programme. ${ }^{45}$ Although $88 \%$ of clubs were familiar with the $\mathrm{NH}$ programme, it was performed fully in only $11 \%$ and partly in just $6 \%$ of the total 150 club seasons included in the study.

The above research findings underpin a wellestablished principle of sports injury prevention: no intervention will achieve its full potential unless it is adopted, correctly implemented and maintained over time. ${ }^{46}$ It has been emphasised that for sports injury prevention measures to succeed, an in-depth understanding of end-user (eg, coach and other programme deliverers) perceptions and the specific implementation context in which the programme takes place is required..$^{15} 4748$

Identification of the factors which influence IPEP implementation can provide valuable information for the design, delivery and support of these programmes, thereby enhancing their success. The tailoring of programmes to specific target groups is also important, with consideration of age, ${ }^{49}{ }^{50}$ knowledge and beliefs, ${ }^{38} 39$ programme length $^{13}$ and climate. ${ }^{13} 26$

This study aimed to identify challenges to implementing IPEPs in the specific context of professional male youth soccer, particularly relating to the established reporting gaps of adoption and maintenance. ${ }^{40}$ As there is currently no industry-standard IPEP for professional soccer, the most highly promoted IPEP for amateur soccer, the FIFA 11+, was used as a blueprint for analysing IPEPs in this study. The specific aims were to:

1. Analyse the perceptions of soccer coaches, fitness coaches and physiotherapists towards injury prevention in general, IPEPs and specifically the FIFA 11+.

2. To seek direct input from staff members regarding the challenges to maintaining IPEPs in their setting.

\section{METHODS}

\section{Study design}

This study was a cross-sectional, web-based survey hosted by Survey Monkey. All participants completed informed consent forms and the study was approved by the Federation University Australia Human Research Ethics Committee (Ballarat, Australia).

\section{Participants}

The targeted participants were all soccer coaches, fitness coaches and physiotherapists working with four elite junior male soccer teams during the 2014/2015 season. The four teams were all based in an elite European soccer academy and were selected based on existing connections with the research team. Three of the teams were competing in the highest national under-age league and one team was competing in the second highest national adult league.

\section{Survey design}

The content and development of the survey has been previously reported. ${ }^{51}$ Briefly, the development was guided by the Reach Effectiveness Adoption Implementation Maintenance (RE-AIM) framework dimensions ${ }^{52}$ and Health Belief Model constructs. ${ }^{53}$ The first section of the survey covered perceptions of LL injury susceptibility and seriousness in soccer and the value of IPEPs in general. In the second section, respondents were prompted to visit the official website of the FIFA 11+ (http://f-marc.com/11plus/home/). Subsequent questions focused specifically on the 
perceived value of the FIFA $11+$ and its relevance to the respondents' context. Both open and closed questions were employed in the survey, including five-point Likert scales, multiple option questions (yes, no, unsure) and questions with free-text answers. The open questions focused on the barriers and facilitators to IPEP maintenance. The survey took approximately $25 \mathrm{~min}$ to complete. Face validity was evaluated by pilot testing the survey on two professional soccer players and two physiotherapists. Face and content validity were also strengthened by the authors' differing backgrounds in professional team sport, epidemiology, implementation research and injury prevention research, along with the previous successful administration of the same survey in another professional soccer setting. ${ }^{51}$

\section{Data collection}

Following approval from the soccer academy's management, all targeted staff members (soccer coaches, fitness coaches and physiotherapists) were invited to participate. The participants completed the survey during the soccer preseason or, in the case of staff changes, when they first joined their team.

\section{Analysis}

The data were exported from Survey Monkey and extensively cleaned and edited. Because of the relatively small sample size and lack of variability, Likert scale responses were converted into three-point scales ('strongly agree/ agree', 'neither agree nor disagree' and 'disagree/ strongly disagree'). The data were analysed with the responses from all four teams combined. Missing responses were excluded. For each survey question, the proportion (\%) of respondents indicating each different answer was calculated in Microsoft Excel and 95\% CIs for the sample proportions were calculated with an online calculator (http://www.select-statistics.co.uk). One author categorised the free-text barriers and facilitators to IPEP maintenance into two themes, identified through a previous thematic analysis of the same survey in an adult male professional soccer setting. ${ }^{51}$ The first theme related to the content and nature of the IPEP itself. The second theme related to the delivery and support of IPEPs at different ecological levels, and responses were further allocated to five subthemes, reflecting different ecological levels in the professional soccer system (player, team staff, club, governing bodies and the external environment). Responses relating to multiple themes or subthemes were allocated to all relevant themes, and the proportions (\%) of total responses allocated to each theme were calculated.

\section{RESULTS}

\section{Participants}

Eighteen $(90 \%)$ of the 20 eligible staff members agreed to participate, with $2(10 \%)$ not participating due to lack of time. The respondents included nine coaches, four fitness coaches and five physiotherapists. From a total of 576 answers across respondents, only $5(<1 \%)$ were missing and hence excluded from the analysis of the particular survey item.

\section{Perceptions of injury susceptibility and injury seriousness}

Very high proportions $(89-100 \%)$ of respondents agreed to statements regarding professional soccer players' high susceptibility to LL injuries and the negative impacts of these injuries (table 1).

\section{Perceptions of IPEPs}

Respondents unanimously agreed that certain LL injuries can be prevented, that evidence-based exercises should be performed by players and that common types of injury prevention exercises such as balance, eccentric strengthening, controlled jumping/landing and cutting can prevent LL injuries (table 1). All respondents believed that these exercises should be varied and progressed over time, and 94\% believed evidence-based exercise should be incorporated into training guidelines.

The multiple-choice question, 'When should exercises to prevent lower limb injuries be performed?' (as part of training, separate from team training, both), was answered with 'both' by $89 \%$ of respondents. The most frequent answers to the question, 'How much time is appropriate for a warm-up session at the start of team training?' were $15 \mathrm{~min} \mathrm{(28 \% ),} 20 \mathrm{~min}(22 \%)$ and $25 \mathrm{~min}$ $(22 \%)$, while four respondents indicated that the appropriate warm-up varied depending on factors such as the content of training and age of the players:

It depends on the content of the team training, the length and intensity should be attuned to the training which follows.

Very variable depending on age. 10-25 mins before the first maximal sprint/shooting action.

\section{Perceptions of injury prevention responsibility}

From eight different soccer club roles listed in the survey, respondents indicated a median of seven different roles as holding responsibility for injury prevention. The most common answers were the player $(100 \%)$, fitness coach $(100 \%)$, physiotherapist $(100 \%)$ and head coach $(94 \%)$. When asked which role holds the ultimate responsibility for injury prevention, the most common answers were the head coach $(35 \%)$, the player $(24 \%)$ and the fitness coach $(24 \%)$.

\section{Perceptions and current practices in relation to the FIFA $11+$}

Sixty-one per cent of respondents had previously heard of the FIFA 11+ (table 2), but less than a third of them reported using it in some form. When asked, 'Does your team currently use the FIFA 11+?' a total of $28 \%$ indicated either 'yes' (6\%) or 'yes, but modified' (22\%). All of the respondents using the programme indicated that 
Table 1 Respondents' perceptions of lower limb (LL) injury susceptibility, injury seriousness and injury prevention exercise programmes, including the Health Belief Model (HBM) constructs ${ }^{53}$ and Reach Effectiveness Adoption Implementation Maintenance (RE-AIM) framework dimensions ${ }^{52}$ which each question related to

\begin{tabular}{|c|c|c|c|c|c|c|c|}
\hline Theme & Statement & $\begin{array}{l}\text { HBM } \\
\text { construct }\end{array}$ & $\begin{array}{l}\text { RE-AIM* } \\
\text { dimension(s) }\end{array}$ & $\mathbf{n}$ & $\begin{array}{l}\text { Agree } \\
\%(95 \% \mathrm{Cl}) \dagger \\
\end{array}$ & $\begin{array}{l}\text { Neither agree nor } \\
\text { disagree } \\
\%(95 \% \mathrm{Cl}) \dagger\end{array}$ & $\begin{array}{l}\text { Disagree } \\
\%(95 \% \mathrm{Cl}) \dagger\end{array}$ \\
\hline \multirow[t]{5}{*}{$\begin{array}{l}\text { Injury susceptibility } \\
\text { and seriousness }\end{array}$} & Soccer players are at high risk of suffering a LL injury & $\begin{array}{l}\text { Perceived } \\
\text { susceptibility }\end{array}$ & $A, M$ & 18 & 94 (90 to 98$)$ & $6(2$ to 10$)$ & 0 \\
\hline & $\begin{array}{l}\text { LL injuries can shorten a professional soccer player's } \\
\text { career }\end{array}$ & $\begin{array}{l}\text { Perceived } \\
\text { seriousness }\end{array}$ & $A, M$ & 18 & 100 & 0 & 0 \\
\hline & $\begin{array}{l}\text { LL soccer injuries can cause physical problems later in } \\
\text { life }\end{array}$ & $\begin{array}{l}\text { Perceived } \\
\text { seriousness }\end{array}$ & $A, M$ & 18 & 100 & 0 & 0 \\
\hline & $\begin{array}{l}\text { LL injuries have a negative impact on team } \\
\text { performance }\end{array}$ & $\begin{array}{l}\text { Perceived } \\
\text { seriousness }\end{array}$ & $A, M$ & 18 & 89 (84 to 94$)$ & $11(6$ to 16$)$ & 0 \\
\hline & $\begin{array}{l}\text { LL injuries have a negative impact on a soccer player's } \\
\text { quality of life }\end{array}$ & $\begin{array}{l}\text { Perceived } \\
\text { seriousness }\end{array}$ & $A, M$ & 18 & 100 & 0 & 0 \\
\hline \multirow[t]{10}{*}{$\begin{array}{l}\text { Injury prevention } \\
\text { exercise programmes }\end{array}$} & It is possible to prevent some LL soccer injuries & $\begin{array}{l}\text { Perceived } \\
\text { benefit }\end{array}$ & $A, E$ & 18 & 100 & 0 & 0 \\
\hline & $\begin{array}{l}\text { Exercises which have been scientifically proven to } \\
\text { prevent LL injuries should be performed by soccer } \\
\text { players }\end{array}$ & $\begin{array}{l}\text { Perceived } \\
\text { benefit }\end{array}$ & $A, M$ & 18 & 100 & 0 & 0 \\
\hline & $\begin{array}{l}\text { Exercises to prevent injuries should be varied and } \\
\text { progressed over time }\end{array}$ & $\begin{array}{l}\text { Cues to } \\
\text { action }\end{array}$ & $A, I, M$ & 18 & 100 & 0 & 0 \\
\hline & $\begin{array}{l}\text { Exercises which have been scientifically proven to } \\
\text { prevent LL injuries should be incorporated into the } \\
\text { club's training guidelines }\end{array}$ & $\begin{array}{l}\text { Cues to } \\
\text { action }\end{array}$ & M & 18 & 94 (90 to 98$)$ & $6(2$ to 10$)$ & 0 \\
\hline & Balance exercises can prevent LL injuries & $\begin{array}{l}\text { Perceived } \\
\text { benefit }\end{array}$ & $E, A, I$ & 18 & 100 & 0 & 0 \\
\hline & Controlled jumping/landing can prevent LL injuries & $\begin{array}{l}\text { Perceived } \\
\text { benefit }\end{array}$ & $E, A, I$ & 18 & 100 & 0 & 0 \\
\hline & Eccentric muscle strengthening can prevent LL injuries & $\begin{array}{l}\text { Perceived } \\
\text { benefit }\end{array}$ & $E, A, I$ & 18 & 100 & 0 & 0 \\
\hline & A warm-up jog/run can prevent LL injuries & $\begin{array}{l}\text { Perceived } \\
\text { benefit }\end{array}$ & $E, A, I$ & 18 & 100 & 0 & 0 \\
\hline & Cutting exercises can prevent LL injuries & $\begin{array}{l}\text { Perceived } \\
\text { benefit }\end{array}$ & $E, A, I$ & 18 & 100 & 0 & 0 \\
\hline & Cool-down jog/run can prevent LL injuries & $\begin{array}{l}\text { Perceived } \\
\text { benefit }\end{array}$ & $E, A, I$ & 18 & 61 (54 to 68$)$ & 17 (11 to 23 ) & 22 (16 to 28$)$ \\
\hline
\end{tabular}

${ }^{*}$ Reach Effectiveness Adoption Implementation Maintenance (RE-AIM) framework: E=effectiveness, $A=$ adoption, I=implementation, M=maintenance.

†In cases of $0 \%$ and $100 \%$ agreement, $95 \%$ Cls calculations returning $(0-0)$ or $(100-100)$ are left blank. 
Table 2 Respondents' awareness, use and perceptions of the FIFA $11+$ programme, including the HBM constructs ${ }^{53}$ and RE-AIM framework dimensions ${ }^{52}$ which each question related to

\begin{tabular}{|c|c|c|c|c|c|c|c|c|c|}
\hline Question or statement & HBM construct & $\begin{array}{l}\text { RE-AIM* } \\
\text { dimension(s) }\end{array}$ & $\mathbf{n}$ & Yes \% $(95 \% \mathrm{Cl}) \dagger$ & No \% $(95 \% \mathrm{Cl}) \dagger$ & $\begin{array}{l}\text { Unsure } \\
\%(95 \% \mathrm{Cl}) \dagger\end{array}$ & $\begin{array}{l}\text { Agree \% } \\
(95 \% \mathrm{Cl}) \dagger\end{array}$ & $\begin{array}{l}\text { Neither agree } \\
\text { nor disagree } \\
\%(95 \% \mathrm{Cl}) \dagger\end{array}$ & $\begin{array}{l}\text { Disagree } \\
\%(95 \% \mathrm{Cl}) \dagger\end{array}$ \\
\hline $\begin{array}{l}\text { Had you heard of the FIFA 11+ } \\
\text { before taking part in this } \\
\text { questionnaire? }\end{array}$ & Cues to action & $\mathrm{R}$ & 18 & 61 (54 to 68) & 39 (32 to 46$)$ & 0 & & & \\
\hline $\begin{array}{l}\text { Does your team currently use the } \\
\text { FIFA } 11+\text { ? }\end{array}$ & Perceived benefit & $\mathrm{R}, \mathrm{A}, \mathrm{M}$ & 18 & $28 \ddagger(22$ to 36$)$ & 61 (54 to 68$)$ & 11 (6 to 16$)$ & & & \\
\hline $\begin{array}{l}\text { Have you ever been in a team } \\
\text { which used the FIFA } 11+?\end{array}$ & Perceived benefit & $\mathrm{R}, \mathrm{A}$ & $13 \S$ & $0 \S$ & 69 (54 to 84$)$ & 31 (16 to 46$)$ & & & \\
\hline $\begin{array}{l}\text { Does the FIFA } 11+\text { need to be } \\
\text { improved for use in your team? }\end{array}$ & Perceived benefit & $\mathrm{A}, \mathrm{I}, \mathrm{M}$ & 17 & 78 (70 to 86$)$ & $6(2$ to 10$)$ & 17 (10 to 24$)$ & & & \\
\hline $\begin{array}{l}\text { Should your club develop its own } \\
\text { version of the FIFA } 11+?\end{array}$ & Cues to action & A, I, M & 17 & 100 & 0 & 0 & & & \\
\hline $\begin{array}{l}\text { The FIFA can prevent LL injuries } \\
\text { in your team }\end{array}$ & Perceived benefit & $\mathrm{E}, \mathrm{A}$ & 18 & & & & 83 (77 to 89 ) & 17 (11 to 23$)$ & 0 \\
\hline The FIFA $11+$ is soccer specific & Perceived benefit & A, I, M & 18 & & & & 50 (43 to 57 ) & 44 (37 to 51$)$ & $6(2$ to 10$)$ \\
\hline The FIFA $11+$ is too long & Perceived barrier & A, I, M & 17 & & & & 6 (2 to 10$)$ & 35 (26 to 44$)$ & 59 (50 to 68$)$ \\
\hline $\begin{array}{l}\text { The FIFA } 11+\text { contains adequate } \\
\text { variation and progression for our } \\
\text { team }\end{array}$ & Perceived benefit & A, I, M & 17 & & & & 22 (14 to 30$)$ & 28 (20 to 36$)$ & 50 (41 to 59$)$ \\
\hline $\begin{array}{l}\text { The FIFA } 11+\text { could be } \\
\text { maintained over multiple } \\
\text { seasons by our team }\end{array}$ & Cues to action & A, I, M & 18 & & & & 44 (37 to 51 ) & 17 (11 to 23 ) & 39 (32 to 46$)$ \\
\hline
\end{tabular}


they liked it, with some providing reasons as free-text answers:

It's simple and the basics are covered. Transparency and comprehensibility are present.

I like it, but I find it too monotonous for regular use.

While $83 \%$ of respondents believed that the FIFA $11+$ could prevent injuries in their team, only half agreed that it is soccer-specific and just $22 \%$ believed it contains adequate variation and progression (table 2). Only $44 \%$ agreed that the FIFA $11+$ could be maintained by their team over multiple seasons. The vast majority of respondents $(78 \%)$ indicated that the FIFA $11+$ needed improvement for use in their team, and there was unanimous agreement that the club should develop its own version (table 2).

In my opinion a standard program is the best option for clubs with minimal medical and sport science staff, to keep the injury rate as low as possible. If possible, players should also perform additional, individual exercises based on grounded, specific test procedures. This needs to be tailored to the specific playing level and age group in question.

\section{Barriers and facilitators to IPEP maintenance}

The barriers and facilitators to IPEP maintenance, categorised by theme and subtheme, are presented in table 3 . The majority of respondents' answers were related to multiple themes and subthemes. Thirty-two per cent of all responses were included under the first theme, the nature and content of the IPEP itself. Almost all responses (97\%) were included under the second theme, IPEP delivery and support. One subtheme, IPEP delivery and support at the team staff level, included $88 \%$ of all responses (table 3 ).

\section{DISCUSSION}

\section{Key results}

This study evaluated the perceptions of IPEP deliverers in the specific context of professional male youth soccer. Soccer coaches, fitness coaches and physiotherapists recognised the high risk and seriousness of soccer injuries and strongly supported the use of evidence-based exercises. Although the majority of respondents had heard of the FIFA 11+ and believed it could prevent injuries in their team, less than a third used it and mostly in a modified form. Overall, the results of this study suggest that established IPEPs need modification for use in professional youth male soccer settings. The findings also hold relevance for the implementation of IPEPs in other soccer settings and in other team ball sports.

\section{Respondents' perceptions of IPEPS}

The participants in this study strongly supported the use of injury prevention exercises in general, with all respondents indicating that soccer players should perform them. This is in accordance with other recent research results in professional soccer settings. ${ }^{31}{ }^{42}$ From 32 national teams participating in the FIFA 2014 World Cup, $91 \%$ reported using IPEPs. ${ }^{42}$ The staff of 44 highlevel professional male teams all reported prescribing IPEPs for their players and their top five rated injury prevention exercise types (eg, eccentric strengthening and balance) corresponded closely to the components of the FIFA $11+{ }^{12} 31$ In the current study, $83 \%$ of respondents thought the FIFA 11+ could prevent injuries in their team. Taken together, these results suggest that IPEPs play an important role in professional soccer and although the FIFA 11+ was designed for amateur players, the types of exercises in the programme also hold relevance for professional soccer settings. Despite this, the respondents' reported use of the FIFA 11+ in its original form $(6 \%)$ or a modified form $(22 \%)$ was very low in this present study.

A potential explanation for these findings is that while the basic FIFA 11+ components, such as strengthening and balance, are relevant to professional teams, the specific exercises need to be adapted to the professional soccer context. Respondents in this study agreed unanimously that injury prevention exercises need to be varied and progressed over time, with only $22 \%$ of respondents believing the FIFA 11+ contained adequate progression and variation. Furthermore, the need for fun and challenging injury prevention exercises, with sufficient variety, was evident in free-text answers.

The delivery of injury prevention exercises may also need tailoring to the professional soccer context. The FIFA $11+$ is delivered as a team warm-up programme, but the majority of participants in this study believed that injury prevention exercises should be delivered both during team training and separate from training. This suggests that the future design and delivery of IPEPs for professional soccer needs to consider various formats for delivering exercises, beyond the warm-up alone. Other studies in professional support these findings. ${ }^{31} 42$ Optimising the individualisation of programmes was the most commonly reported injury prevention challenge in a survey of 2014 FIFA World Cup teams, ${ }^{42}$ and $73 \%$ of premier league professional soccer teams reported prescribing both individual and group injury prevention sessions. ${ }^{31}$

\section{Barriers and facilitators to IPEP maintenance}

Far more clues to the specific implementation challenges in professional soccer emerged from the free-text answers regarding IPEP maintenance. The diversity and nature of the reported challenges highlight that efficacious IPEPs alone are not enough to prevent injuries. Almost all responses related to aspects of programme delivery and support (eg, coach acceptance, communication and team work). Hence, to ensure the ultimate success of these programmes, there is a need to focus on addressing implementation challenges at various levels of the soccer system. 
Table 3 Barriers and facilitators to injury prevention exercise programme (IPEP) maintenance in professional soccer teams categorised by themes and subthemes, including the proportion (\%) of total responses included under each theme

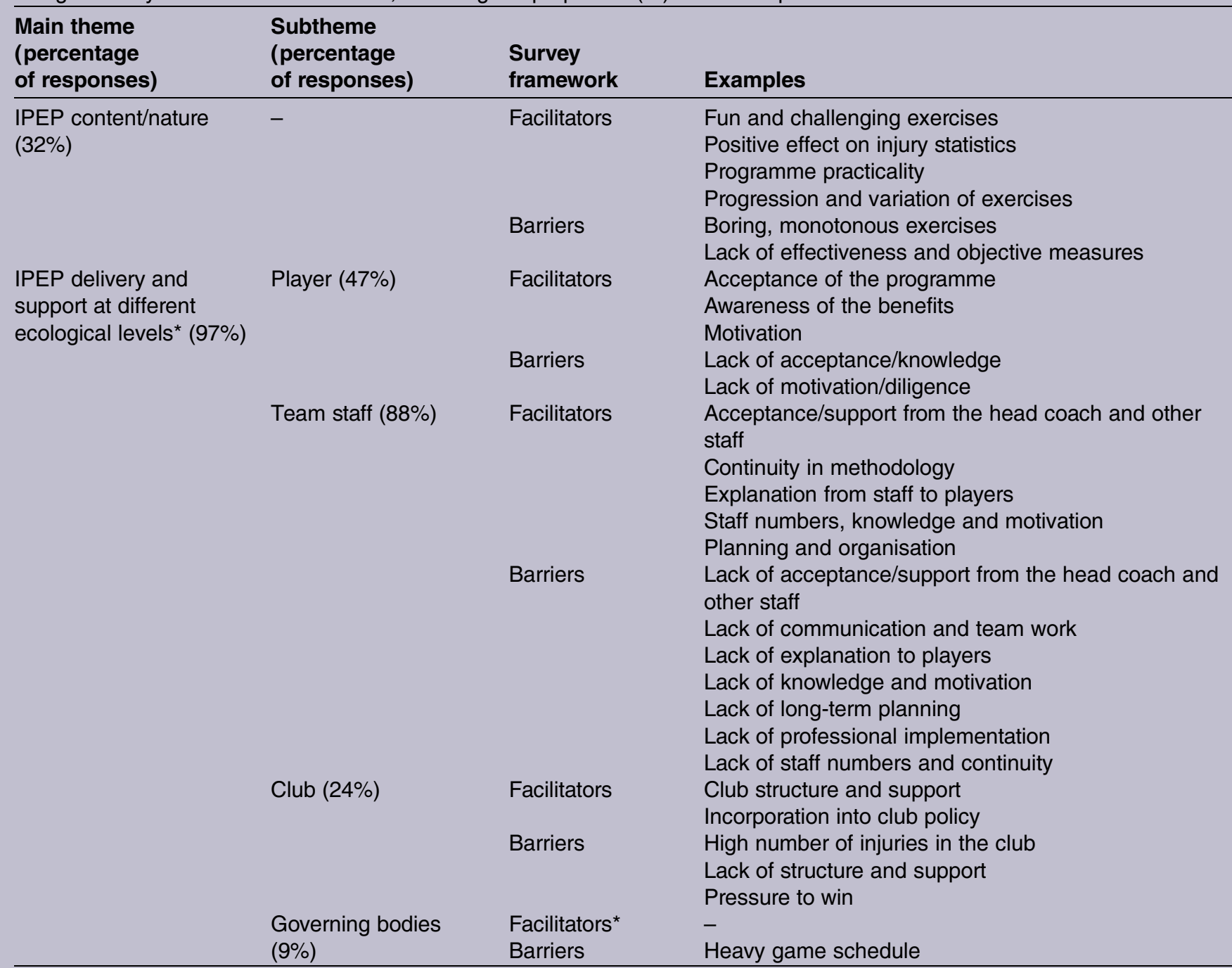

*The categories governing bodies/facilitators was included because it arose in a previous study using the same survey, but no respondents in the current study provided relevant responses. There were also no relevant responses for the previously identified subtheme 'external environment'.

It is noteworthy that one subtheme, IPEP delivery and support at team staff level, included $88 \%$ of all responses. Examples in this subtheme included staff acceptance of IPEPs, staff number and continuity, communication and team work. The frequency of responses in this sub theme strongly suggests that factors at staff level represent a key challenge in the successful maintenance of IPEPs in professional youth soccer. The presence of large interdisciplinary teams in professional sports clubs and the potential for conflict among these teams has been previously reported. ${ }^{32} 5455$ The high number of roles sharing the responsibility for injury prevention in clubs, as indicated by the respondents in this study, adds to the challenge of ensuring adequate acceptance and support for IPEPs. Physicians working with 2014 FIFA World Cup teams identified 'compliance of and between staff' as one of the main challenges in preventing injuries. ${ }^{42}$ Research reports from the Union of European Football Associations (UEFA) injury study, involving top-level professional European teams, have also identified internal communication and the stability of staffing as important elements for successful injury prevention. $^{43}$

\section{Limitations}

This study had several limitations. The sample size, which was dictated by the targeted real-world setting, was small. Accordingly, care is warranted in extrapolating the study results to other populations. The small sample size also precluded analysis of participant subgroups (eg, coaches only), or potential modifying variables (eg, age, coaching experience) due to insufficient power. The survey used in this study was not subjected to validity testing beyond face and content validity, similar to other studies in this field, ${ }^{31} 4142$ though the same survey was successfully conducted in a group of professional adult 
soccer teams. ${ }^{51}$ The answers to Likert scale questions may have been influenced by factors such as acquiescence bias and social desirability bias. ${ }^{56}$ Only one researcher allocated free-text responses to themes and subthemes, and the use of multiple independent reviewers may have strengthened this method.

\section{Future research}

Further studies are needed to investigate exactly how IPEPs are used in professional youth soccer settings and the specific implementation challenges they face. As reported injury prevention behaviour does not necessarily reflect actual behaviour, ${ }^{57}$ direct observation of IPEP use through longitudinal observational studies, with multiple assessment times, is recommended. Such studies will provide insight into exactly how IPEPs are modified by end users and the specific reasons behind these modifications.

\section{CONCLUSION}

The coaches, fitness coaches and physiotherapists of professional youth male soccer teams strongly support the use of injury prevention exercise programmes. However, to enhance their impact, IPEPs must be tailored to the specific implementation context of professional youth soccer. This includes modifying IPEP content to provide adequate exercise challenge, variation and progression. Additionally, adequate delivery and support of IPEPs at various levels, particularly team staff level, are key considerations. The results of this study provide valuable information for enhancing the delivery of existing exercise programmes and also for the future development of improved IPEPs for professional youth soccer.

\section{Twitter Follow James 0'Brien at @_jamesobrien Follow Caroline Finch} @CarolineFinch

Contributors $\mathrm{JO}$ led this work as part of his PhD studies. He designed the study, led its conduct, had the major role in paper writing and is responsible for the overall content as guarantor. CFF contributed to the design of the study and the writing of the paper.

Funding JO is supported by a Federation University Australia Postgraduate Scholarship. CFF is supported by an NHMRC Principal Research Fellowship (ID: 1058737). The Australian Centre for Research into Injury in Sport and its Prevention (ACRISP) is one of the International Research Centres for Prevention of Injury and Protection of Athlete Health supported by the International Olympic Committee (IOC).

Competing interests $\mathrm{JO}$ is employed at the professional soccer academy involved in this study. Although all survey responses were anonymous, it is possible that the author's relationship to academy staff influenced the results.

Ethics approval Federation University Australia Human Ethics Committee.

Provenance and peer review Not commissioned; internally peer reviewed.

Data sharing statement No additional data are available.

Open Access This is an Open Access article distributed in accordance with the Creative Commons Attribution Non Commercial (CC BY-NC 4.0) license, which permits others to distribute, remix, adapt, build upon this work noncommercially, and license their derivative works on different terms, provided the original work is properly cited and the use is non-commercial. See: http:// creativecommons.org/licenses/by-nc/4.0/

\section{REFERENCES}

1. Fédération Internationale de Football Association. Big count. http:// www.fifa.com/worldfootball/bigcount/ (accessed 11 Sept 2015).

2. Ekstrand J, Hägglund M, Waldén M. Injury incidence and injury patterns in professional football: the UEFA injury study. $\mathrm{Br} J$ Sports Med 2011;45:553-8.

3. Hägglund $M$, Waldén $M$, Magnusson $\mathrm{H}$, et al. Injuries affect team performance negatively in professional football: an 11-year follow-up of the UEFA Champions League injury study. Br J Sports Med 2013;47:738-42.

4. Kuijt MT, Inklaar H, Gouttebarge V, et al. Knee and ankle osteoarthritis in former elite soccer players: a systematic review of the recent literature. J Sci Med Sport 2012;15:480-7.

5. von Porat A, Roos EM, Roos $\mathrm{H}$. High prevalence of osteoarthritis 14 years after an anterior cruciate ligament tear in male soccer players: a study of radiographic and patient relevant outcomes. Ann Rheum Dis 2004;63:269-73.

6. Lohmander LS, Ostenberg A, Englund M, et al. High prevalence of knee osteoarthritis, pain, and functional limitations in female soccer players twelve years after anterior cruciate ligament injury. Arthritis Rheum 2004;50:3145-52.

7. Junge $A$, Lamprecht $M$, Stamm $\mathrm{H}$, et al. Countrywide campaign to prevent soccer injuries in Swiss amateur players. Am J Sports Med 2011;39:57-63.

8. Waldén $\mathrm{M}$, Atroshi I, Magnusson $\mathrm{H}$, et al. Prevention of acute knee injuries in adolescent female football players: cluster randomised controlled trial. BMJ 2012;344:e3042.

9. Soligard T, Myklebust G, Steffen K, et al. Comprehensive warm-up programme to prevent injuries in young female footballers: cluster randomised controlled trial. BMJ 2008;337:a2469.

10. Owoeye OB, Akinbo SR, Tella BA, et al. Efficacy of the FIFA 11+ warm-up programme in male youth football: a cluster randomised controlled trial. J Sports Sci Med 2014;13:321-8.

11. Silvers-Granelli $\mathrm{H}$, Mandelbaum $\mathrm{B}$, Adeniji $\mathrm{O}$, et al. Efficacy of the FIFA $11+$ injury prevention program in the collegiate male soccer player. Am J Sports Med 2015;43:2628-37.

12. Bizzini M, Dvorak J. FIFA 11+: an effective programme to prevent football injuries in various player groups worldwide-a narrative review. Br J Sports Med 2015;49:577-9.

13. Twomey DM, Doyle TL, Lloyd DG, et al. Challenges when implementing an evidence-based exercise injury prevention training program in community-level sport. J Appl Case Stud Sport Exerc Sci 2015;1:29-39.

14. Twomey D, Finch C, Roediger E, et al. Preventing lower limb injuries: is the latest evidence being translated into the football field? $J$ Sci Med Sport 2009;12:452-6.

15. Finch CF, White $\mathrm{P}$, Twomey $\mathrm{D}$, et al. Implementing an exercise-training programme to prevent lower-limb injuries: considerations for the development of a randomised controlled trial intervention delivery plan. Br J Sports Med 2011;45:791-6.

16. White PE, Otago L, Saunders N, et al. Ensuring implementation success: how should coach injury prevention education be improved if we want coaches to deliver safety programmes during training sessions? Br J Sports Med 2014;48:402-3.

17. Saunders N, Otago L, Romiti M, et al. Coaches' perspectives on implementing an evidence-informed injury prevention programme in junior community netball. Br J Sports Med 2010;44:1128-32

18. Myklebust G, Skjølberg A, Bahr R. ACL injury incidence in female handball 10 years after the Norwegian ACL prevention study: important lessons learned. Br J Sports Med 2013;47:476-9.

19. Finch CF, Diamantopoulou K, Twomey DM, et al. The reach and adoption of a coach-led exercise training programme in community football. Br J Sports Med 2014;48:718-23.

20. Yank V, Stafford RS, Rosas LG, et al. Baseline reach and adoption characteristics in a randomized controlled trial of two weight loss interventions translated into primary care: a structured report of real-world applicability. Contemp Clin Trials 2013;34:126-35.

21. White SM, McAuley E, Estabrooks PA, et al. Translating physical activity interventions for breast cancer survivors into practice: an evaluation of randomized controlled trials. Ann Behav Med 2009;37:10-19.

22. Rao JK, Anderson LA. Examining external validity in efficacy and secondary articles of home-based depression care management interventions for older adults. Prev Chronic Dis 2012;9:E172.

23. Gaglio B, Shoup JA, Glasgow RE. The RE-AIM framework: a systematic review of use over time. Am J Public Health 2013;103: e38-46.

24. Hägglund $M$, Atroshi I, Wagner $P$, et al. Superior compliance with a neuromuscular training programme is associated with fewer ACL 
injuries and fewer acute knee injuries in female adolescent football players: secondary analysis of an RCT. Br J Sports Med 2013;47:974-9.

25. Soligard T, Nilstad A, Steffen K, et al. Compliance with a comprehensive warm-up programme to prevent injuries in youth football. Br J Sports Med 2010;44:787-93.

26. Steffen $\mathrm{K}$, Emery $\mathrm{CA}$, Romiti $\mathrm{M}$, et al. High adherence to a neuromuscular injury prevention programme (FIFA 11+) improves functional balance and reduces injury risk in Canadian youth female football players: a cluster randomised trial. $\mathrm{Br} J$ Sports Med 2013;47:794-802.

27. Gabbe BJ, Branson R, Bennell KL. A pilot randomised controlled tria of eccentric exercise to prevent hamstring injuries in community-leve Australian Football. J Sci Med Sport 2006;9:103-9.

28. Engebretsen $\mathrm{AH}$, Myklebust $\mathrm{G}$, Holme I, et al. Prevention of injuries among male soccer players: a prospective, randomized intervention study targeting players with previous injuries or reduced function. Am J Sports Med 2008;36:1052-60.

29. Myklebust G, Engebretsen L, Braekken IH, et al. Prevention of anterior cruciate ligament injuries in female team handball players: a prospective intervention study over three seasons. Clin J Sport Med 2003;13:71-8.

30. Bizzini M, Junge A, Dvorak J. Implementation of the FIFA 11+ football warm up program: how to approach and convince the Football associations to invest in prevention. Br J Sports Med 2013;47:803-6.

31. McCall A, Carling C, Nedelec M, et al. Risk factors, testing and preventative strategies for non-contact injuries in professional football: current perceptions and practices of 44 teams from various premier leagues. Br J Sports Med 2014;48:1352-7.

32. Silva AA, Bittencourt NF, Mendonça LM, et al. Analysis of the profile, areas of action and abilities of Brazilian sports physical therapists working with soccer and volleyball. Rev Bras Fisioter 2011;15:219-26.

33. Owen AL, Wong del $\mathrm{P}$, Dellal $\mathrm{A}$, et al. Effect of an injury prevention program on muscle injuries in elite professional soccer. $J$ Strength Cond Res 2013;27:3275-85.

34. Joy EA, Taylor JR, Novak MA, et al. Factors influencing the implementation of anterior cruciate ligament injury prevention strategies by girls soccer coaches. J Strength Cond Res 2013;27:2263-9.

35. Norcross MF, Johnson ST, Bovbjerg VE, et al. Factors influencing high school coaches' adoption of injury prevention programs. J Sci Med Sport Published online first: 01 April 2015. doi: 10.1016/j. jsams.2015.03.009

36. LaBella CR, Huxford MR, Grissom J, et al. Effect of neuromuscular warm-up on injuries in female soccer and basketball athletes in urban public high schools: cluster randomized controlled trial. Arch Pediatr Adolesc Med 2011;165:1033-40.

37. Owoeye OBA, Akinbo SRA, Olawale OA, et al. Injury prevention in football: knowledge and behaviour of players and availability of medical care in a Nigerian youth football league. S Afr J Sports Med 2013;25:77-80.

38. McKay CD, Steffen K, Romiti M, et al. The effect of coach and player injury knowledge, attitudes and beliefs on adherence to the FIFA 11+ programme in female youth soccer. Br J Sports Med 2014;48:1281-6.

39. Orr B, Brown C, Hemsing J, et al. Female soccer knee injury: observed knowledge gaps in injury prevention among players/ parents/coaches and current evidence (the KNOW study). Scand J Med Sci Sports 2013;23:271-80.

40. O'Brien J, Finch CF. The implementation of musculoskeletal injury-prevention exercise programmes in team ball sports: a systematic review employing the RE-AIM framework. Sports Med 2014;44:1305-18

41. Lindblom $\mathrm{H}$, Waldén $\mathrm{M}$, Carlfjord $\mathrm{S}$, et al. Implementation of neuromuscular training programme in female adolescent football: 3-year follow-up study after a randomised controlled trial. $\mathrm{Br} J$ Sports Med 2014:48:1425-30.

42. McCall A, Davison M, Andersen TE, et al. Injury prevention strategies at the FIFA 2014 World Cup: perceptions and practices of the physicians from the 32 participating national teams. $\mathrm{Br} J$ Sports Med 2015;49:603-8.

43. Ekstrand J, Hägglund $\mathrm{M}$, Kristenson $\mathrm{K}$, et al. Fewer ligament injuries but no preventive effect on muscle injuries and severe injuries: an 11-year follow-up of the UEFA Champions League injury study. $\mathrm{Br} \mathrm{J}$ Sports Med 2013;47:732-7.

44. Frank BS, Register-Mihalik J, Padua DA. High levels of coach intent to integrate a ACL injury prevention program into training does not translate to effective implementation. J Sci Med Sport 2015;18:400-6.

45. Bahr R, Thorborg K, Ekstrand J. Evidence-based hamstring injury prevention is not adopted by the majority of Champions League or Norwegian Premier League football teams: the Nordic Hamstring survey. Br J Sports Med 2015;49:1466-71.

46. Finch $\mathrm{C}$. A new framework for research leading to sports injury prevention. J Sci Med Sport 2006;9:3-9.

47. Donaldson A, Finch CF. Applying implementation science to sports injury prevention. Br J Sports Med 2013;47:473-5.

48. Verhagen E, Finch CF. Setting our minds to implementation. $\mathrm{Br}$ Sports Med 2011;45:1015-16.

49. Hammes D, Aus der Fünten K, Kaiser S, et al. Injury prevention in male veteran football players - a randomised controlled trial using "FIFA 11+". J Sports Sci 2015;33:873-81.

50. Kilding AE, Tunstall H, Kuzmic D. Suitability of FIFA's "The 11" training programme for young football players-impact on physical performance. J Sports Sci Med 2008;7:320-6.

51. O'Brien J. Finch CF. (in press). Injury prevention exercise programs for professional soccer: understanding the perceptions of the endusers. Clin J Sport Med

52. Virginia Polytechnic Institute and State University. RE-AIM. http:// www.re-aim.org/ (accessed 15 Sept 2015).

53. Hayden J. Health belief model. In: Hayden J. Introduction to health behavior theory. Sudbury, MA: Jones and Bartlett Learning, 2008:31-44

54. Reid C, Stewart E, Thorne G. Multidisciplinary sport science teams in elite sport: comprehensive servicing or conflict and confusion? Sport Psych 2004;18:204-17.

55. Elphinston J, Hardman SL. Effect of an integrated functional stability program on injury rates in an international netball squad. J Sci Med Sport 2006;9:169-76.

56. Dimitrov DM. Statistical methods for validation of assessment scale data in counseling and related fields. Alexandria, VA: American Counseling Association, 2012.

57. Eime R, Finch $\mathrm{C}$, Owen N, et al. Do squash players accurately report use of appropriate protective eyewear? J Sci Med Sport 2005;8:352-6. 